\title{
Periodontal Stem Cells: a Historical Background and Current Perspectives
}

\author{
Sandu Pitaru • A. Sampath Narayanan • \\ Anusha Etikala • Sandra Treves-Manusevitz \\ Published online: 27 December 2013 \\ (C) Springer International Publishing AG 2013
}

\begin{abstract}
In this review we discuss the historical perspective of stem cell populations from oral tissues in light of our current understanding of stem cell biology. Stem cells and their niches have been identified in the periodontium starting from the late 1970s. Applying new criteria for the identification and characterization reveals that oral tissues comprise a multipotent primitive neural crest-like stem cell population capable of differentiating into neural crest derived cell lineages of the cranial-facial zone. This population supplies cells to a more restricted stem cell type with tissue specific epigenetic memory that differentiates into cell lineages characteristic of their tissue origin. We believe that the microenvironment plays an essential role in maintaining stem cell populations and directing their migration and differentiation, and that this factor needs to be considered for utilization of stem cell-based therapy for periodontal regeneration and regenerative dental medicine.
\end{abstract}

Keywords Stem cells · Progenitors · Stem cell niche ·

Microenvironment $\cdot$ Extracellular matrix $\cdot$ Stem cell

differentiation - Oral mucosa Periodontal ligament .

Gingiva $\cdot$ Alveolar bone $\cdot$ Cementum $\cdot$ Endosteal space $\cdot$

Paravascular zone $\cdot$ Periodontal regeneration $\cdot$ Neural crest

S. Pitaru $\cdot$ S. Treves-Manusevitz

Department of Oral Biology, Maurice and Gabriela Goldschleger

School of Dental Medicine, Ramat Aviv, Tel Aviv 69978, Israel

S. Pitaru

e-mail: pitaru@post.tau.ac.il

S. Treves-Manusevitz

e-mail: sandraharel@gmail.com

A. S. Narayanan $(\bowtie) \cdot$ A. Etikala

Department of Pathology, University of Washington School of

Medicine, Seattle, WA 98195-7470, USA

e-mail: sampath@uw.edu

A. Etikala

e-mail: anusun.anusun@gmail.com

\section{Introduction}

Stem cell biotechnology has become an active research area for the development of novel therapeutic strategies in regenerative dental medicine. Recent advances in stem cell biology have made it possible to identify stem cell niches in the oral/dental tissues, and stem cells have been isolated from dental pulp, periodontal ligament, gingiva and oral mucosa $[1 \bullet, 2,3,4 \bullet \bullet, 5]$. Although these are relatively newer efforts, the concept of a dividing population within periodontal tissues capable of supplying new cells for homeostasis and wound healing is not new. Indeed, the idea was originally conceptualized more than 35 years ago by investigators such as Weiss et al. [6] and Brunette et al. [7]. Here we review the historical perspective of the evolution of stem cell biology in dental research. We also highlight the importance of interactions between stem cells and their progenies with matrix components available in the microenvironment for their selection and differentiation.

\section{Stem Cells: Definitions and Types}

Two important characteristics that distinguish stem cells from other cells are the ability to self-renew without losing development potential, and to give rise to multiple differentiated cell types $[8-10,11 \bullet \cdot$. Stem cells can divide for long periods without differentiating, and under certain physiologic or experimental conditions they can be induced to become tissueor organ-specific cells with special functions. Two major stem cell types are the embryonic stem cells and adult stem cells. The embryonic stem cells are pluripotent and capable of differentiating into cells of the three germ layers in vitro and in vivo, and theoretically can give rise to any cell type of the body. In contrast, adult stem cells are multipotent and they differentiate into a restricted number of cell lineages derived 
from the same germ layer that gave rise to the specific adult stem cell. The adult stem cells, also called somatic stem cells, are present in virtually all tissues, including muscle and brain. The large majority of these cells are believed to divide relatively slowly in most tissues under homeostatic conditions; however, in tissues such as epithelium in the small intestine they divide at a fast rate and cycle continuously. The slow cycling adult stem cells respond to wounding and stress by cycling faster and dividing asymmetrically to produce tissuerestricted progenitors and differentiated cells in order to replace destroyed cells [10, 11••].

Recently, pluripotency was induced in adult cells, including those from the teeth, by transducing them with the transcription factors Oct4, Sox2, c-Myc and Klf4; these cells, called induced pluripotent stem cells (iPS), are currently under intensive study [12-15].

\section{Stem Cells of Oral Tissues-a Retrospective Analysis in the Perspective of Current Knowledge}

\section{Periodontal Ligament}

The concept of "stem cells" in adult oral tissues can be traced back to the identification of a subset of cycling populations that possessed self-renewal characteristics with extensive proliferative capacity in epithelial tissues: oral epithelium, junctional epithelium, salivary glands, ectomesenchymally derived tissue lamina propria of the oral mucosa, pulp, and the attachment apparatus of the oral cavity [6, 16-19]. In the late 1970s and early 1980s, Melcher's group at the University of Toronto focused on the biology of the periodontium with specific emphasis on the periodontal ligament. This group was the first to culture periodontal ligament cells from porcine premolars and demonstrate that cells located within periodontal ligament explants adjacent to blood vessels incorporate $\left[\mathrm{H}^{3}\right]$-thymidine and could migrate to the culture dish, where they further proliferated to form a periodontal ligament cell culture [7]. Almost 40 years later paravascular (or perivascular) cells expressing mesenchymal stem cell markers Stro1 and CD146 have been identified in the human periodontal ligament [20], demonstrating that the cultures generated by Brunette et al. [7] comprised, at least in part, stem cells. To the best of our knowledge this was the first attempt to show that the perivascular zone might be the niche for periodontal ligament stem cells, similar to adult mesenchymal stem cells located in bone marrow, fat and other tissues [8, 21-23]. Melcher's group also found a pool of mitotic cells in the vicinity of blood vessels following wounding of the alveolar bone and periodontal ligament that shifted within the repopulated wound area $[24,25]$; this provided evidence for the presence of progenitor/stem cells within the perivascular niche in the periodontal ligament that respond to wounding.
The current paradigm is that tissue specific stem cell populations isolated in vitro should be tested in functional experiments for capacity to develop into the tissue of origin [22]. In 1981, Boyko et al. [26], possibly influenced by the work of Till and McCulloch [27], demonstrated that periodontal ligament progenitors isolated by explantation and loaded on the denuded roots in vitro formed new periodontium when implanted in an edentulous ridge in the dog. This was the first controlled functional experiment that provided evidence for the existence of a functional stem cell population within the periodontal ligament in particular, and oral cavity in general, and the first experiment demonstrating the feasibility and benefit of stem cells expanded in vitro for periodontal regeneration.

The existence of a progenitor/stem cell population(s) in the perivascular zone of the mammalian periodontal ligament during homeostasis has been extensively investigated by McCulloch, Melcher and their coworkers [18, 28-32]. Their fundamental work proved that: (1) the perivascular zone contains a population of cycling cells part of which migrates towards the cementum, the ligament itself and the bone where they possibly contribute to the cementoblastic, fibroblastic and osteoblastic lineages of the periodontal ligament, respectively $[18,28]$; (2) this perivascular population comprises a subpopulation of slow cycling cells located closest to the vascular wall [30]; (3) endosteal cells of the alveolar bone located in the vicinity of blood vessels cycle and migrate into periodontal ligament to contribute to perivascular pool of cycling cells [31]; (4) a non-vascular related zone of cycling cells close to the cementum; (5) cell renewal is compensated by cell death, suggesting that the periodontal ligament cell population is in a steady state during homeostasis [32]. Therefore, it can be conceived that, similar to other highly active tissues like the hematopoietic tissue, intestinal epithelium and hair follicle [11••], the periodontal ligament comprises two stem cell populations located in adjacent but separate compartments: a quiescent slow cycling population located in the near vicinity of the blood vessels (within $10 \mu \mathrm{m}$ of the vessels wall) and an active stem cell population located in the paravascular zone but outside the $10-\mu \mathrm{m}$ boundary (Fig. 1). The concept of quiescent and active stem cell populations explains the long term preservation of a stem cell pool within the tissue (the quiescent population) that replenishes the "hard working" active stem cell pool which cycles faster to supply cells to the transient amplifying populations [9, 11••]. Thus, the cycling cell population located adjacent to the bone and cementum may be transient amplifying cells derived from the active stem cell pool (Fig. 1). This hypothesis raises the following questions: (1) What is the niche and what are the molecular cues that maintain these populations in their respective states? (2) What stimuli cause the cells to move from one compartment to another? (3) Are the quiescent and active populations endowed with same potency (stemness)? (4) 

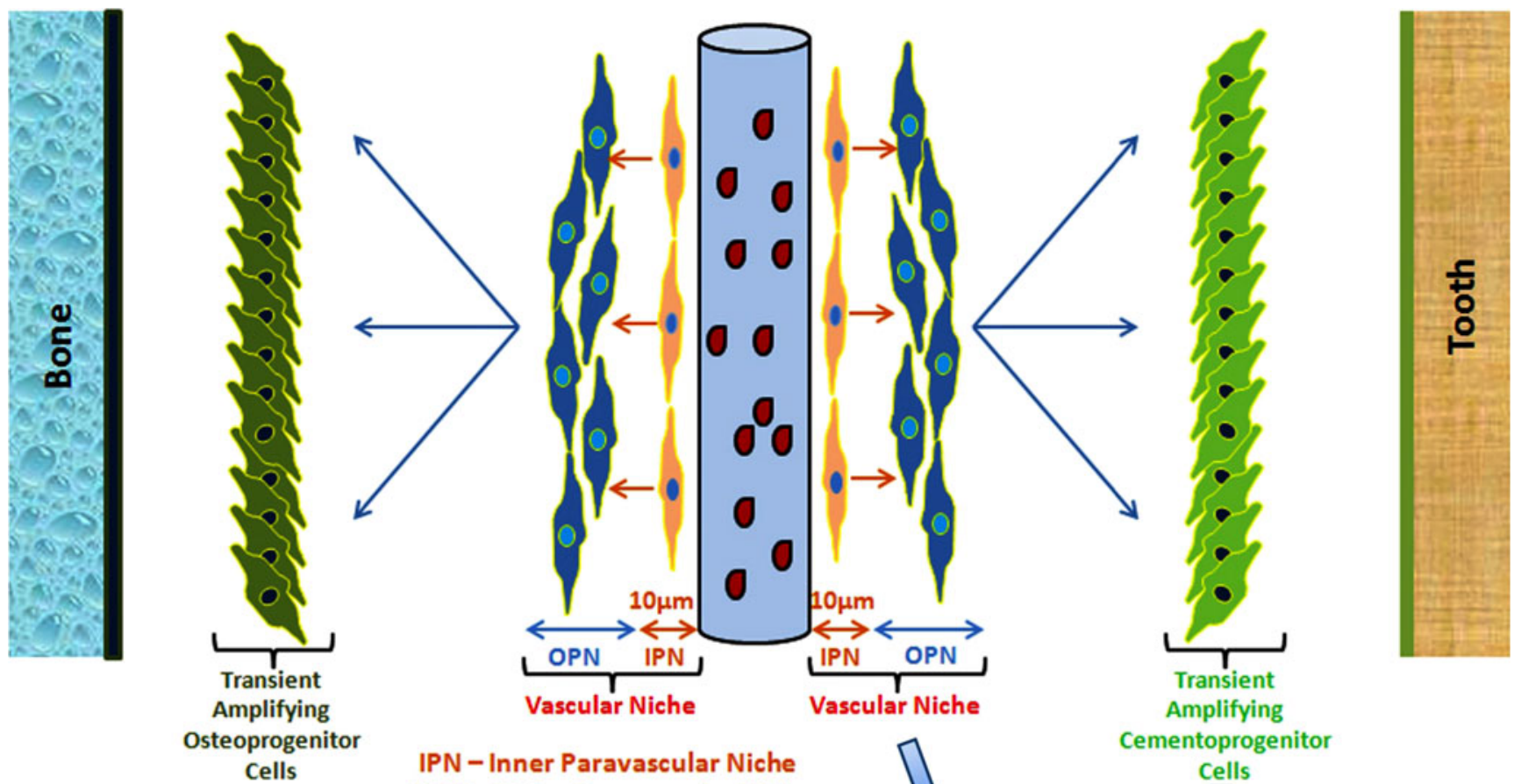

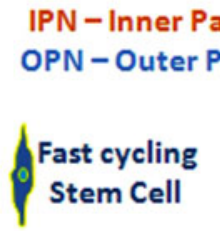

IPN - Inner Paravascular Niche OPN - Outer Paravascular Niche

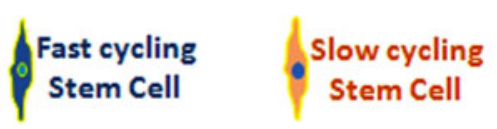

\section{S-Stem cells of paravascular niche P1 and P2 - Differentiating amplifying cells $\mathrm{Cb}$ - Fully differentiating cementoblasts}

Fig. 1 Stem cell niches and stem cell differentiation illustrated using adult periodontal ligament model. Two stem cell systems co-exist in the paravascular zone: (1) the first system resides in the inner paravascular niche (IPN) in the close vicinity (within $10 \mu \mathrm{m}$ ) of blood vessels. It consists of slow cycling cells (orange); (2) the second system resides peripherally to the $10-\mu \mathrm{m}$ boundary in an outer paravascular niche (OPN). It comprises fast cycling cells (blue) that divide symmetrically and asymmetrically to supply the pool and provide new cells to the transient amplifying population (green). This hierarchical structure ensures the preservation of the stem cell population and fast reaction of the cycling population to homeostatic demands and unexpected external stimuli. The transient amplifying population maintains epigenetic memory acquired during their migration to their target tissue: cementum, bone

What are the cells that migrate into the periodontal ligament from endosteal spaces of the alveolar bone and what is their role? (5) What are the molecular cues that direct their migration? (6) What are the cells that are isolated as periodontal ligament stem cells in vitro?

A hallmark of stem cells is their clonal properties. Approximately $42 \%$ of cultured adult human periodontal ligament cells are clonogenic which could be expanded by over 222 and periodontal ligament (the last is not shown). Upon induction of $\mathrm{BMP}_{2}$ secreted by periodontal ligament cells (PDLC) of ectomesenchymal and/ or ectodermal (epithelial rests of Malassez) origin, stem cells of the paravascular niche $(S)$ exit the niche and migrate along a cementum attachment protein $(C A P)$ gradient. This gradient is formed by migrating, proliferating and differentiating transient amplifying cells $(P 1$ and $P 2)$ and by fully differentiating cementoblasts $(\mathrm{Cb})$. The secretion of CAP, which is cell lineage specific, is induced by $\mathrm{BMP}_{2}$ secreted by the PDLC. In addition to its chemotactic effect, the CAP exerts paracrine and autocrine effects on the differentiation of the cementoblastic progenitors. The CAP is one example of molecules that participate in the differentiation process, and the final outcome is the sum total of the effects of all such molecules

doublings [33]; therefore, these clones could represent cultured stem cell population of the periodontal ligament. About $20 \%$ of these putative stem cells do not differentiate into mineralized tissue in the presence of dexamethasone unless they were first induced with $\mathrm{BMP}_{2}$ [34]. These observations further support the existence of a primitive multipotent common stem cell for fibroblastic, cementoblastic and osteoblastic lineages in the periodontal ligament. 
Advances in the identification and understanding of the biology of mesenchymal (stromal) stem cells in the bone marrow $[35,36]$ paved the way to the identification and characterization of mesenchymal stem cells from cultures from adult dental pulp [2] and periodontal ligament [37]. A putative multipotent stem cell population isolated from adult human periodontal ligament by cell sorting, using the perivascular pericyte markers Stro- 1 and CD146 differentiates into osteoblastic and adipogenic lineages in vitro [38, 39]; however, when transplanted subcutaneously into immunodeficient mice, this population develops into periodontal-like tissues consisting of a cementum-like tissue, bone and a periodontal like tissue with Sharpey's fiber inserted into the bone. These findings, in which cells with certain stem cell properties and ability to recapitulate periodontal development in an ectopic site was isolated, strengthen the results and concepts of Melcher's and McCulloch's groups.

\section{The Alveolar Bone}

Although the kinetic study of McCulloch et al. [31] pointed to the existence of a cycling population within the endosteal spaces in mice, it is only recently that stromal cells have been isolated from human, canine and murine mandibles and alveolar bone [40-42]. The stromal alveolar bone marrow cells proliferate faster, have higher capacity to form single cellderived colonies and differentiate into the osteoblastic lineage in culture relative to bone marrow cells derived from the iliac crest or long bones, but they have lower propensity to differentiate into chondroblastic and adipocytic lineages. When implanted in ectopic sites in immunodeficient mice the stromal alveolar bone marrow cells form bone without the hematopoietic component and with less bone marrow space than the stromal bone marrow cells from long bones or iliac crest. These observations indicate that alveolar bone derived stromal cell cultures are more restricted in their multilineage differentiation potency than non-oral skeleton bone marrow stromal cells. However, they appear to be more potent in new bone formation. Whether the stem/progenitor cells isolated in culture represent the stem cells observed by McCulloch [31] that migrate from the endosteal spaces through the vascular channels into the periodontal ligament, and possibly contribute to the homeostasis and repair, remains to be elucidated.

\section{The Oral Mucosa}

The oral mucosa consists of the oral epithelium and lamina propria. The oral epithelium contains a basal cell layer attached to the basal membrane that comprises a stem cell compartment; this supplies new cells to the overlying epithelial tissue. The nature of the oral epithelium (keratinized or nonkeratinized) is dictated by the lamina propria of the various oral mucosa types - masticatory and lining. The composition and instructive properties of the lamina propria differs in various oral zones indicating heterogeneity in the fibroblast populations [43, 44]. Studies on cell populations of rodent gingival lamina propria indicate the existence of a stem cell/progenitor compartment adjacent to blood vessels [45] similar to the periodontal ligament and alveolar bone. These cells also exhibit clonal migration. In hamsters, approximately $44 \%$ of the cells in the gingival lamina propria cycle in vivo and in vitro, and upon explantation additional $\sim 39 \%$ start cycling in vitro [46]; this indicates the existence of a dormant population activated by culture conditions. Clinical observations indicate that incisional and excisional surgical wounds in oral mucosa heal substantially faster than wounds in other connective tissues $[47,48]$. These wounds heal by regeneration without scar formation similar to fetal tissues and adult tissues of low vertebrates [47].

In contrast to other tissues, in healthy subjects with no habits (e.g. smoking), the oral mucosa exhibits marginal signs of aging at the clinical [49] and cellular levels [50]. The proliferation rate of oral mucosa derived-fibroblasts is not affected by aging [51]. These observations and the findings that fibroblasts of the lamina propria exhibit fetal-like migratory and extracellular matrix (ECM) organization characteristics $[48,52,53]$ indicate the existence of a fetal-like population in the lamina propria of the adult oral mucosa which is preserved during adult life. These findings and the hierarchical structure of cell populations $[9,54]$ further indicate that a primitive, possibly multipotent/pluripotent, population is present at the top of these fetal-like populations. Based on these principles, we have reported the existence of a putative pluripotent population derived from the lamina propria of either the masticatory or lining oral mucosa [55]. Widera et al. [56] identified Klf4 and c-Myc, two of four transcription factors used to generate iPS, in the human palate, further strengthening the notion of a primitive stem cell population harnessed in the lamina propria of the oral mucosa. These authors also generated a cell population derived from the rat palate capable of forming proliferating neurospheres and expressing neural crest markers, suggestive of neural crest-derived stem cells in the rat oral mucosa. Marynka-Kalmani et al. $[4 \bullet \cdot]$ provided the first strong evidence for the presence of a primitive neural crest-like stem cell population within the lamina propria of the adult human oral mucosa and gingiva. Apparently, this population - termed human oral mucosa-derived stem cells (hOMSC) - appears to be a mixed population. Approximately $50 \%$ of the hOMSC express the pluripotency associated markers Oct4, Sox 2 and Nanog and the embryonic markers SSEA4, Tra2-49 and Tra2-54. The entire population expresses the classical mesenchymal stem cell markers CD29, CD73, CD90 and CD105. When transplanted into immunodeficient SCID mice, the hOMSC develop to most of the tissues known to be derived from the neural crest including bone, cartilage, fat, neural tissues and fibrous tissue. In addition, myogenic 
and epithelial tissues were also identified. Interestingly, these tissues form a two-lineage teratoma-like structure reminiscent of the true three-lineage teratoma formed by embryonic stem cells transplanted into scid mice. The hOMSC are highly clonogenic ( 1 out of 1.7 cells give rise to clones); therefore these are likely to be stem cells [4••]. Davies et al. [57] also demonstrated the neural crest origin of clonogenic cells derived from lamina propria of the oral mucosa and their multipotent differentiation into mesenchymal and neuroectodermal cell lineages. However, several other studies have reported that mesenchymal stem cells transplanted on hydroxyapatite/tricalcium phosphate into nude mice develop only into fibrous tissue [58]. These apparently contracting data can be explained by the existence of two different populations in expandable cells isolated from the gingiva: (1) a primitive multipotent neural crest like population [4••, 57]; (2) a less potent and more restricted mesenchymal stromal population [58] reminiscent of transient amplifying cells. This notion has been recently addressed by $\mathrm{Xu}$ et al. [59], who demonstrated by lineage tracing that two such populations coexist in the gingiva and that the neural crest-derived population cycles and forms the majority of the clonogenic cells in vitro. Notably, mesenchymal stem cells isolated from adult human pulp and periodontal ligament $[2,37,60]$ develop into dentin-pulp complex, cementum and periodontal ligamentlike tissues, respectively. On the other hand, both pulp and periodontal ligament stem cells express neural crest properties $[61,62]$ and exhibit a high propensity to differentiate into neural lineages $[60,63]$, indicating the existence of a primitive neural crest-like stem cell population in the pulp and periodontal ligament. Collectively, these data show that the mesenchymal stem cells isolated from oral tissues based on Stro-1 and CD146 expression represent a restricted and less potent stem/progenitor cell population that proliferates faster in culture but retains tissue-specific epigenetic memory.

\section{Stem Cell Niche and Stem Cell Differentiation}

In vivo, stem cells reside in specific microenvironments or niches that maintain their ground base status, "stemness". Within their niche, stem cells are normally believed to divide asymmetrically into a new stem cell (self-renewal) and a committed progenitor with restricted developmental potential and closer to its final fate. In Drosophila and Caenorhabditis elegans a single population of germ cells resides in a single niche [64] cycling constantly until nutritionally challenged; in contrast, in higher organisms stem cells reside in tissuespecific niches in an actively growing or quiescent state [11••].

The fate of the stem cells is determined by many factors, which include polypeptide mediators, microenvironment, tensional forces and interaction with other cells [65-68]. The polypeptide mediators are the major agonists that determine, regulate and direct cell functions, and this family includes growth factors, cytokines and lymphokines. However, how the cells respond to these molecules depends upon their microenvironment. The microenvironment of the niche regulates stem cell survival and renewal, and it also regulates their differentiation at the destination site. It consists of the ECM and molecules that remain bound to and associated with it. The ECM is a three-dimensional structure composed of collagens, fibronectin, elastin, laminin and other noncollagenous proteins and proteoglycans, and it serves as substratum for cell adhesion, promotes cell spreading and cytoskeletal organization $[65,66$, 69]. More importantly, it determines the outcome of a cell's response to agonists by regulating the expression of genes for growth factors, receptors, transcription factors and other proteins. For example, in the presence of ECM cell division is suppressed and cells differentiate $[65,66,69]$. The ECM, through its constituent collagen types and adhesive and antiadhesive proteins, can selectively recruit specific cell types and exclude others from among a population of stem/progenitor cells and mesenchymal cell subtypes [66, 70-72, 73•].

The molecular interactions and signaling cues between stem cells and their niches have been studied for some tissues, such as the hair follicle, intestinal crypt and bone marrow [11••, 74]. In these tissues, cycling and quiescent stem cells are located in discrete niches/zones. The niches provide a microenvironment with stimulatory or inhibitory stimuli. For example, bone marrow contains hematopoietic stems cells (HSC) and mesenchymal stem cells (MSC). There are two niches for HSCs: (1) the osteoblastic niche containing quiescent HSCs in the endosteal region, and (2) the vascular niche located in the central marrow region and containing active HSCs [74]. The osteoblastic niche supports and maintains the HSCs, regulates hematopoiesis, and provides a microenvironment for quiescence, whereas the vascular niche promotes proliferation and further differentiation, and serves as a backup niche for HSC expansion. The endosteal zone is composed of osteoblastic, vascular, CXCL12 abundant reticular (CAR) cells and osteoclasts, and the signals are largely inhibitory through Wnt-off/BMP-on signaling that promote quiescence. In contrast, the central marrow region is without osteoblastic signals and is growth stimulatory mediated chiefly by Wnt, FGF and SDF1. In general BMP, osteopontin and sFRP1 signals are inhibitory while Wnt signals and noggin promote an active state [11••]. Stem cell regulation also involves apoptosis signaling [75].

The signals involved in the crosstalk between the stem cell populations and their niche and those controlling the migration and differentiation of various cell lineages within the periodontal ligament and gingiva are unknown. Very little is also known about the nature and role of the microenvironment. Recent findings indicate that epithelial cell rests of Malassez (ERM) retain stem cell properties and possibly secrete and respond to soluble factors in the adult periodontium [76-78]. It would be of interest to determine whether 
morphological and functional interactions exist between the ERM and stem cell niche in the periodontal ligament. It is also likely that fibroblastic populations in the periodontal ligament form the niche is required for the maintenance of ERM in the adult periodontal tissues.

Another intriguing question is about the mechanisms that instruct a stem cell to leave the paravascular niche and migrate towards the cementum and bone. A gradient of chemotactic factors are possibly involved in this process. Evidence indicates that cementum proteins in combination with $\mathrm{BMP}_{2}$ are possible soluble factors involved in the chemotaxis and differentiation to cementoblastic lineage (Fig. 1) [33, 34, 66, 79-83].

The stem cells niche in the gingiva has been recently located to cord-like structure comprising cells positive to the neural crest marker p75 and to pluripotency associated markers Oct4 and Nanog [4••]. Nestin positive cells are located in the subepithelial papillae of the palatal rugae in Meissner Corpuscles and Merkel cell-neurite complexes and in apical papilla of immature permanent teeth [56, 84]. These cells bear properties of multipotent stem cells indicating the presence of stem cells in a neural related niche. Under physiological microenvironment, the gingival stem cells differentiate into the "fibroblastic lineages" of the gingiva [43, 85]. However, after release from their niche the remote microenvironment containing cementum attachment protein appears to influence these cells to form a mineralized-like structure and express cementoblastic /osteoblastic markers (our unpublished data). When transplanted into immunocompromised mice these cells form a cementum-like tissue with ECM characteristic of the cementum [86]. These observations underscore the crucial role played by the microenvironment in the selective recruitment of stem/progenitor cells, their expansion and subsequent differentiation $[65,66,73 \bullet]$.

\section{Conclusion and Future Perspectives}

Although pluripotent embryonic stem cells are the cells of choice because of their therapeutic plasticity, adult stem-/ progenitor cells from the same tissue are preferable to avoid ethical and legal issues because these are closer to the differentiative target, and they can be obtained from same patients. It is now clear that the main component necessary for regeneration of oral tissues, the cells - stem cells or progenitors - are available in the local niches. What appears lacking is the needed local microenvironment, which is destroyed by injury and not restored during the wound healing process. Therefore, if the reservoir of stem cells capable of regenerating the destroyed tissues is sufficiently large, finding ways to recruit these cells and control their differentiation and lineage commitment in time and space is the next challenge for periodontal and tooth regeneration research. The oral mucosa heals by regeneration, indicating that, similar to liver, its regenerative capacity is preserved in the adult. This occurs even though wounding of the oral mucosa takes place in a bacterially contaminated environment. We need to gain further insight into the molecular and cellular mechanisms that govern wound healing in the oral mucosa and apply this knowledge to periodontal and pulp-dentin complex wound healing. These challenges are also relevant for regenerative medicine in general. However, controlling the spatialtemporal behavior of stem cells in the wound healing environment might prove a difficult task. Advances in the biology of oral stem cells teach us that all the oral tissues comprise pools of multipotent stem cells with high level of plasticity. Thus, obtaining stem cells from one or more of these tissues, delivering them at the right time and place and manipulating them in vitro to the desired stage of differentiation is a feasible task capable of opening new horizons in the field of oral/dental and periodontal regenerative medicine.

Acknowledgments We thank Rina Kazakov for her help in preparing this review. This work was supported by the US-Israel Binational Foundation, grant no. 2011017, Israeli Science Foundation grants 646/09 and 384/13, and NIH grants DE 13069, DE-08229, DE-013061 and DE39584.

\section{Compliance with Ethics Guidelines}

Conflict of Interest Dr. Sandu Pitaru and Dr. Sandra TrevesManusevitz received grants from BSF (\#2011017, 646/09 and 384/13).

Dr. Sampath Narayanan and Dr. Anusha Etikala, received grants from NIH (DE 13069, DE-08229, DE-013061, and DE39584).

Human and Animal Rights and Informed Consent This article does not contain any studies with human or animal subjects performed by any of the authors.

\section{References}

Papers of particular interest, published recently, have been highlighted as:

- Of importance

•• Of major importance

1. Estrela C, Alencar AH, Kitten GT, Vencio EF, Gava E. Mesenchymal stem cells in the dental tissues: perspectives for tissue regeneration. Braz Dent J. 2011;22:91-8. This review provides a historical evolution of stem cells from various dental tissues and their prospective use in regenerative dental medicine.

2. Gronthos S, Mankani M, Brahim J, Robey PG, Shi S. Postnatal human dental pulp stem cells (DPSCs) in vitro and in vivo. Proc Natl Acad Sci U S A. 2000;97:13625-30.

3. Huang GT, Gronthos S, Shi S. Mesenchymal stem cells derived from dental tissues vs. those from other sources: their biology and role in regenerative medicine. J Dent Res. 2009;88:792-806.

4.• Marynka-Kalmani K, Treves S, Yafee M, Rachima H, Gafni Y, Cohen MA, et al. The lamina propria of adult human oral mucosa harbors a novel stem cell population. Stem Cells. 2010;28:984-95. 
This is the first comprehensive report demonstrating that the human adult oral mucosa harbors a primitive stem cell population with neural crest characteristics capable of giving rise to cell lineages derived from the cephalic neural crest.

5. Bartold PM, Shi S, Gronthos S. Stem cells and periodontal regeneration. Periodontology 2000. 2006;40:164-72.

6. Weiss R, Stahl SS, Tonna EA. Functional demands on the cell proliferative activity of the Periodontium studied autoradiogaphically. J Dent Res. 1968;47:1153-7.

7. Brunette DM, Melcher AH, Moe HK. Culture and origin of epithelium-like and fibroblast-like cells from porcine periodontal ligament explants and cell suspensions. Arch Oral Biol. 1976;21: 393-400.

8. Bianco P, Robey PG, Simmons PJ. Mesenchymal stem cells: revisiting history, concepts, and assays. Cell Stem Cell. 2008;2:313-9.

9. Weissman IL. Stem cells: units of development, units of regeneration, and units in evolution. Cell. 2000;100:157-68.

10. Wager AJ, Weissman IL. Plasticity of adult stem cells. Cell. 2004;1116:639-48.

11.• Li L, Clovers H. Coexistence of quiescent and active adult stem cells in mammals. Science. 2010;327:542-5. This article describes how pools of stem cells are maintained in quiescent and active states in niches of different tissues and discusses the molecular signals involved.

12. Takahashi K, Yamanaka S. Induction of pluripotent stem cells from mouse embryonic and adult fibroblast cultures by defined factors. Cell. 2006;126:663-76.

13. Takahashi K, Tanabe K, Ohnuki M, Narita M, Ichisaka T, Tomoda $\mathrm{K}$, et al. Induction of pluripotent stem cells from adult human fibroblasts by defined factors. Cell. 2007;131:861-72.

14. Oda Y, Yoshimura Y, Ohnishi H, Tadokoro M, Katsube Y, Sasao M, et al. Induction of pluripotent stem cells from human third molar mesenchymal stromal cells. J Biol Chem. 2010;285:29270-8.

15. Wada N, Wang B, Lin NH, Laslett AL, Gronthos S, Bartold PM. Induced pluripotent stem cell lines derived from human gingival fibroblasts and periodontal ligament fibroblasts. J Periodontal Res. 2011;46:438-47.

16. Pinzon RD, Toto PD, O'Malley T, O'Malley JJ. Kinetics of rat molar pulp cells at various ages. J Dent Res. 1966;45:934-8.

17. Palmon A, David R, Neumann Y, Stiubea-Cohen R, Krief G, Aframian DJ. High-efficiency immunomagnetic isolation of solid tissue-originated integrin-expressing adult stem cells. Methods. 2012;56:305-9.

18. McCulloch CAG, Melcher AH. Continuous labeling of the periodontal ligament of mice. J Periodontal Res. 1983;18:231-41.

19. Pitaru S, McCulloch CAG, Narayanan AS. Cellular origins and differentiation control mechanisms during periodontal development and wound healing. J Periodontal Res. 1994;29:81-94.

20. Chen SC, Marino V, Gronthos S, Bartold PM. Location of putative stem cells in human periodontal ligament. J Periodontal Res. 2006;41:547-53.

21. Crissan M, Yap S, Casteilla L, et al. A perivascular origin for mesenchymal stem cells in multiple human organs. Cell Stem Cell. 2008;3:301-13.

22. Bianco P, Cao X, Frenette PS, et al. The meaning, the sense and the significance: translating the science of mesenchymal stem cells into medicine. Nat Med. 2013;13:31-42.

23. Zannettino AC, Paton S, Arthur A, Khor F, Itescu S, Gimble JM, et al. Multipotential human adipose-derived stromal stem cells exhibit a perivascular phenotype in vitro and in vivo. J Cell Physiol. 2008;214:413-21.

24. Gould TRL, Melcher AH, Brunette DM. Location of progenitor cells in periodontal ligament of mouse molar stimulated by wounding. Anat Rec. 1977;188:133-41.

25. Gould TRL, Melcher AH, Brunette DM. Migration and division of progenitor cell populations in periodontal ligament after wounding. J Periodontal Res. 1980;15:20-42.
26. Boyko GA, Melcher AH, Brunette DM. Formation of new periodontal ligament by periodontal ligament cells implanted in vivo after culture in vitro. J Periodontal Res. 1981;16:73-88.

27. Till JE, McCulloch EA. A direct measurement of the radiation sensitivity of normal mouse bone marrow cells. Radiat Res. 1961;14:213-22.

28. McCulloch CAG, Melcher AH. Cell migration in the periodontal ligament of mice. J Periodontal Res. 1983;18:339-52.

29. McCulloch CAG, Melcher AH. Cell density and cell generation in the periodontal ligament of mice. Am J Anat. 1983;167:43-58.

30. McCulloch CAG. Progenitor cell populations in the periodontal ligament of mice. Anat Rec. 1985;211:258-62.

31. McCulloch CAG, Nemeth E, Lowenberg B, Melcher AH Paravascular cells in endosteal spaces of alveolar bone contribute to periodontal ligament cell populations. Anat Rec. 1987;219:233-42.

32. McCulloch CAG, Barghava U, Melcher AH. Cell death and the regulation of populations of cells in the periodontal ligament. Cell Tissue Res. 1989;255:129-38.

33. Liu HW, Yacobi R, Savion N, Narayanan AS, Pitaru S. A collagenous cementum-derived attachment protein is a marker for progenitors of the mineralized tissues -forming cell lineage of the periodontal ligament. J Bone Miner Res. 1997;12:1691-9.

34. Pitaru S, Pritzki A, Bar-Kana I, Grosskopf A, Savion N, Narayanan AS. Bone morphogenetic protein 2 induces the expression of cementum attachment protein in human periodontal ligament clones. Connect Tissue Res. 2002;43:257-64.

35. Pittenger MF, Mackay AM, Beck SC, Jaiswal RK, Douglas R, Mosca JD, et al. Multilineage potential of adult human mesenchymal stem cells. Science. 1999;284:143-7.

36. Colter DC, Sekiya I, Prockop DJ. Identification of a subpopulation of rapidly self-renewing and multipotential adult stem cells in colonies of human marrow stromal cells. Proc Natl Acad Sci U S A. 2001;98:7841-5.

37. Seo BM, Miura M, Gronthos S, Bartold PM, Batouli S, Brahim J, et al. Investigation of multipotent postnatal stem cells from human periodontal ligament. Lancet. 2004;364:149-55.

38. Simmons PJ, Torok-Storb B. Identification of stromal cell precursors in human bone marrow by a novel monoclonal antibody STRO-1. Blood. 1991;78:55-62.

39. Gronthos S, Zannettino AC, Graves SE, Ohta S, Hay SJ, Simmons PJ. Differential cell surface expression of the STRO-1 and alkaline phosphatase antigens on discrete developmental stages in primary cultures of human bone cells. J Bone Miner Res. 1999;14:47-56.

40. Matsabura T, Suardita K, Ishii M, et al. Alveolar bone marrow as a cell source for regenerative medicine: Differences between alveolar and iliac bone marrow stromal cells. J Bone Miner Res. 2005;20: 399-409.

41. Akintoye SO, Lam T, Shi S, Brahim J, Collins MT, Robey PG. Skeletal site-specific characterization of orofacial and iliac crest human bone marrow stromal cells in same individuals. Bone. 2006;38:758-68.

42. Yamaza T, Ren G, Akiyama K, Chen C, Shi Y, Shi S. Mouse mandible contains distinctive mesenchymal stem cells. J Dent Res. 2011;90:317-24.

43. McCulloch CAG, Bordin S. Role of fibroblast subpopulations in periodontal physiology and pathology. J Periodontal Res. 1991;26: 144-54.

44. Lekic PC, Pender N, McCulloch CA. Is fibroblast heterogeneity relevant to the health, diseases, and treatments of periodontal tissues? Crit Rev Oral Biol Med. 1997;8:253-68.

45. Pender N, Heaney TG. Migration and proliferation of progenitor cells in the connective tissue of rat gingival papilla. J Periodontal Res. 1995;30:312-8.

46. McCulloch CA, Knowles G. Discrimination of two fibroblast progenitor populations in early explant cultures of hamster gingiva. Cell Tissue Res. 1991;264:87-94. 
47. Hallock GG. In utero cleft lip repair in A/J mice. Plast Reconstr Surg. 1985;75:785-8.

48. Stephens P, Davies KJ, al-Khateeb T, Shepherd JP, Thomas DW. A comparison of the ability of intra-oral and extra-oral fibroblasts to stimulate extracellular matrix reorganization in a model of wound contraction. J Dent Res. 1966;75:1358-64.

49. Wolff A, Ship JA, Tylenda CA, Fox PC, Baum BJ. Oral mucosal appearance is unchanged in healthy, different-aged persons. Oral Surg Oral Med Oral Path. 1991;71:569-72.

50. Cruchley AT, Williams DM, Farthing PM, Speight PM, Lesch CA, Squier CA. Langerhans cell density in normal human oral mucosa and skin: relationship to age, smoking and alcohol consumption. J Oral Pathol Med. 1994;23:55-99.

51. Solmi R, Tietz C, Zucchini C, Gualandi G, Pugnaloni A, et al. In vitro study of gingival fibroblasts from normal and inflamed tissue: age-related responsiveness. Mech Age Dev. 1996;92:31-41.

52. Schor SL, Ellis I, Irwin CR, Banyard J, Seneviratne K, Dolman C, et al. Subpopulations of fetal-like gingival fibroblasts: characterization and potential significance for wound healing and the progression of periodontal disease. Oral Dis. 1996;2:155-66.

53. Irwin CR, Picardo M, Ellis I, Sloan P, Grey A, McGurk M, et al. Inter- and intra-site heterogeneity in the expression of fetal-like phenotypic characteristics by gingival fibroblasts: potential significance for wound healing. J Cell Sci. 1994;107:1333-46.

54. Lajtha LG, Gilbert CW, Porteous DD, Alexanian R. Kinetics of a bone marrow stem-cell population. Ann NY Acad Sci. 1964;113:742-52.

55. Marynka K, Treves S, Pitaru S. Human oral mucosa is highly enriched with pluripotent stem cells. Presented at the Sixth ISSCR Annual Meeting. Philadelphia, PA, 2008.

56. Widera $\mathrm{D}$, Zander $\mathrm{C}$, Heidbreder M, et al. Adult palatum as a novel source of neural crest-related stem cells. Stem Cells. 2009;27:1899 910.

57. Davies LC, Locke M, Webb RD, Roberts JT, Langley M, Thomas DW, et al. A multipotent neural crest-derived progenitor cell population is resident within the oral mucosa lamina propria. Stem Cells Dev. 2010;19:819-30.

58. Zhang Q, Shi S, Liu Y, Uyanne J, Shi Y, Shi S, et al. Mesenchymal stem cells derived from human gingiva are capable of immunomodulatory functions and ameliorate inflammation-related tissue destruction in experimental colitis. J Immunol. 2009;18:7787-98.

59. Xu X, Chen C, Akiyama K, Chai Y, Le AD, Wang Z, et al. Gingivae contain neural-crest- and mesoderm-derived mesenchymal stem cells. J Dent Res. 2013;92:825-32.

60. Miura M, Gronthos S, Zhao M, Lu B, Fisher LW, Robey PG, et al. SHED: stem cells from human exfoliated deciduous teeth. Proc Natl Acad Sci U S A. 2003;100:5807-12.

61. Stevens A, Zuliani T, Olejnik C, LeRoy H, Obriot H, Kerr-Conte J, et al. Human dental pulp stem cells differentiate into neural crestderived melanocytes and have label-retaining and sphere-forming abilities. Stem Cells Dev. 2008;17:1175-84.

62. Dangaria SJ, Ito Y, Luan X, Diekwisch TG. Successful periodontal ligament regeneration by periodontal progenitor preseeding on natural tooth root surfaces. Stem Cells Dev. 2011;20:1659-68.

63. Coura GS, Garcez RC, Mendes de Aguiar CBN, Alvarez-Silva M, Magini RS, Trentin AG. Human periodontal ligament: a niche of neural crest stem cells. J Periodontal Res. 2008;43:531-6.

64. Kimble JE, White G. On the control of germ cell development in Caenorhabditis elegans. Dev Biol. 1981;81:208-19.

65. Discher DE, Mooney DJ, Zandstra PW. Growth factors, matrices, and forces combine and control stem cells. Science. 2009;324:1673-7.

66. Grzesik WJ, Narayanan AS. Cementum and periodontal wound healing and regeneration. Crit Rev Oral Biol Med. 2002;13:474-84.

67. Engler AJ, Sen S, Sweeney HL, Discher DE. Matrix elasticity directs stem cell lineage specification. Cell. 2006;126:677-89.

68. Jung Y, Song J, Shiozawa Y, et al. Hematopoeitic stem cells regulate mesenchymal stromal cell induction into osteoblasts thereby participating in the formation of the stem cell niche. Stem Cells. 2008;26:2042-51.

69. Sastry SK, Horwitz AF. Adhesion-growth factor interactions during differentiation: an integrated biological response. Dev Biol. 1996;180:455-67.

70. Metzger Z, Weinstock B, Dotan M, Narayanan AS, Pitaru S. Differential chemotactic effect of cementum attachment protein on periodontal cells. J Periodontal Res. 1998;33:126-9.

71. Olson S, Arzate H, Narayanan AS, Page RC. Cell attachment activity of cementum proteins and mechanism of endotoxin inhibition. J Dent Res. 1991;70:1272-7.

72. Pitaru S, Narayanan AS, Olson S, Savion N, Hekmati H, Alta I, et al. Specific cementum attachment protein enhances selectively the attachment and migration of periodontal cells to root surfaces. J Periodontal Res. 1995;30:360-8.

73. Greenbaum LE, Wells RG. The role of stem cells in liver repair and fibrosis. Int J Biochem Cell Biol. 2011;43:222-9. This review highlights the cellular and functional plasticity of stem/progenitor cell niche in the liver, and the role of the cross-talk between these cells and other cells, especially myofibroblasts, and matrix in regeneration and fibrosis.

74. Yin T, Li L. The stem cell niches in bone. J Clin Invest. 2006;116: 1195-201

75. Fuchs Y, Brown S, Gorenc T, et al. Sept4/ARTS regulates stem cell apoptosis and skin regeneration. Science. 2013;341:286-9.

76. Sonoyama W, Seo BM, Yamaza T, Shi S. Human Hertwig's epithelial root sheath cells play crucial roles in cementum formation. J Dent Res. 2007;86:594-9.

77. Xiong J, Mrozik K, Gronthos S, Bartold PM. Epithelial cell rests of Malassez contain unique stem cell populations capable of undergoing epithelial-mesenchymal transition. Stem Cells Dev. 2012;21: 2012-25.

78. Xiong J, Gronthos S, Bartold PM. Role of the epithelial cell rests of Malassez in the development, maintenance and regeneration of periodontal ligament tissues. Periodontol 2000. 2013;63:217-33.

79. BarKana I, Narayanan AS, Grosskop A, Savion N, Pitaru S. Cementum attachment protein enriches putative cementoblastic populations on root surfaces in vitro. J Dent Res. 2000;79:1482-8.

80. Komaki M, Iwasaki K, Arzate H, Narayanan AS, Izumi Y, Morita I. Cementum protein 1 (CEMP1) induces a cementoblastic phenotype and reduces osteoblastic differentiation in periodontal ligament cells. J Cell Physiol. 2012;227:649-57.

81. Kémoun P, Laurencin-Dalicieux S, Rue J, et al. Human dental follicle cells acquire cementoblast features under stimulation by BMP-2/-7 and enamel matrix derivatives (EMD) in vitro. Cell Tissue Res. 2007;329:283-94.

82. Handa K, Saito M, Tsunoda A, Yamauchi M, Hattori S, Sato S, et al. Progenitor cells from dental follicle are able to form cementum matrix in vivo. Connect Tissue Res. 2002;43:406-8.

83. Villarreal-Ramírez E, Moreno A, Mas-Oliva J, Chávez-Pacheco JL, Narayanan AS, Gil-Chavarría I, et al. Characterization of recombinant human cementum protein 1 (hrCEMP1): primary role in biomineralization. Biochem Biophys Res Commun. 2009;384:49-54.

84. Sonoyama W, Liu Y, Yamaza T, Tuan RS, Wang S, Shi S, et al. Characterization of the apical papilla and its residing stem cells from human immature permanent teeth: a pilot study. J Endod. 2008;34:166-71.

85. Bordin S, Page RC, Narayanan AS. Heterogeneity of normal human diploid fibroblasts: isolation and characterization of one phenotype. Science. 1984;223:171-3.

86. Treves-Manusevitz S, Hoz L, Rachima H, Montoya G, Tzur E, Vardimon A, et al. Stem cells of the lamina propria of human oral mucosa and gingiva develop into mineralized tissues in vivo. J Clin Periodontol. 2013;40:73-81. 